\title{
Penggunaan Teknik permainan Peran Dalam Bimbingan Kelompok Untuk Meningkatkan Percaya Diri di PAUD IAIN Parepare
}

\author{
Desti Nurhidayah \\ Prodi Manajemen Dakwah \\ IAIN Parepare
}

\section{PENDAHULUAN}

Pendidikan Taman Kanak-kanak atau yang populer saat ini dengan istilah pendidikan anak usia dini (PAUD), pada dasarnya adalah sebuah sistem pendidikan yang diselenggarakan dengan tujuan untuk menfasilitasi pertumbuhan dan perkembangan anak secara menyeluruh atau menekankan pada perkembangan seluruh aspek kepribadian anak. Pendidikan anak usia dini PAUD memberikan kesempatan kepada anak untuk mengembangkan kepribadiannya.

Dengan adanya bimbingan akan membantu seorang anak luar biasa untuk bisa lebih terampil, mandiri dan tidak tergantung kepada orang lain. Keberhasilan anak dimulai ketika anak memasuki Taman Kanak-kanak karena di Taman Kanakkanak anak dapatbereksplorasi, menggali kemampuan yang dimilikinya, menunjukkan kemampuan rasa percaya diri sehingga pola pikir dan kemampuan yang dimiliki anak menjadi berkembang dan meningkat. Kemampuan yang dikembangkan di PAUD adalah kemampuan kognitif, sosial, rasa percaya diri dan fisik motorik.

Dari adanya kemampuan tersebut yang dapat ditingkatkan dengan menggunakan permainan peran dengan kata lain kemampuan rasa percaya diri.rasa percaya diri penting bagi anak, karena dengan anak mempunyai rasa percaya diri dapat menyelesaikan suatu pekerjaan dan masalah, setelah anak dapat menyelesaikan suatu pekerjaan dan masalah anak akan lebih percaya diri. Rasa percaya diri memberi peran banyak dan penting bagi anak. Anak mempunyai rasa percaya diri bila ada yang memotivasi, memberikan stimulus atau rangsangan tentang rasa percaya diri kepada anak sehingga anak akan terbiasa percaya diri dan mempunyai rasa percayadiri yang tinggi. Namun sebaliknya, apabila anak tidak mempunyai rasa percaya diri anak akan tumbuh menjadi pribadi yang kurang sehat dan mandiri.

Kemampuan rasa percaya diri anak PAUD Pada umumnya anak-anak secara bertahap berubah dari melakukan berbicara didepan bersama-sama lalu mau bermain bersama-sama untuk menunjukan kemampuannya, berkembang menjadi mempunyai percaya diri melalui : (1) Memperlihatkan rasa senang; (2) Bersedia memberi dan menerina bantuan; (3) Berani berbicara didepan kelas; (4) Berani menyatakan sesuatu 
secara langsung dan terus terang. Anak-anak biasanya mampu mengembangkan rasa percaya diri melalui bermain bersama dan mengobrol sama teman.

Dengan adanya bimbingan kelompok dapat memberikan pertolongan kepada setiap anak anak untuk dapat memahami bahwa orang lain ternyata mempunyai kebutuhan kebutuhan dan masalah masalah yang sama berhubungan dengan aspek rasa percaya diri. Melalui bimbingan kelompok akan dapat membantu masalah anak anak yang berkaitan dengan kepercayaan diri. Hal ini di tandai dengan kemampuan rasa percaya diri pada anak PAUD masih malu-malu jika disuruh maju ke depan kelas masih malu, belajar di sekolah sendiri, cara berteman anak masih mau menangnya sendiri. Penyebab rendahnya kemampuan rasa percaya diri pada anak di PAUD IAIN Pareparekarena pembelajaran yang disampaikan guru pada anak masih monoton, kurang bervariasi, kurang menarik, sehingga membuat anak menjadi bosan dan minat belajarnya menjadi berkurang.

Meningkatkan rasa percaya diri sangat perlu dalam berperilaku, ketika seseorang kurang percaya diri itu cenderung tidak mudah melakukan sesuatu hal tetapi tergantung kepada orang lain bagaimana cara menanggapi orang lain ketika kurang mampu menyesuaikan diri secara emosional. Dalam hal tersebut anak anak pada dasarnya perlu di asah kemampuan karna kepercayaan diri sangat berpengaruh pada dirinya

Masa kanak kanak merupakan masa dasar pembentukan kepribadian yang di bentuk. Pada dasarnya anak anak masih membutuhkan penilaian terhadap tingkah lakunya. Jika anak mendapat pujian atas anak akan merasa senang dan percaya diri. Orang tua dan lingkungan memegang peran penting dalam membentuk kepercayaan diri anak. Seringkali orang tua memberikan laranganpada anak untuk melakukansesuatu, sehingga keberanian anak kurang berkembang dengan baik

Kepercayaan diri merupakan salah satu kunci keberhasilanseseorang dan menjadi hal dasar yang penting untuk di kuasai oleh anak anak.kepribadian. kemampuan bersosialisasi ,dan kecerdasan bersumber dari. Ketidakpercayaan diri pada anak jika dibiarkanakan menghambat perkembangan jiwa pada anak. Sejak dini anak memang perlu dilatih sebaik mungkin agar ketika melakukan sesuatu hal anak mengerti apa yang harus mereka lakukan dengan kepercayaan diri atau keberanian yang di miliki.

Berdasarkan permasalahan-permasalahan yang terjadi yang disebutkan dilatar belakang, membuat peneliti tertarik untuk melakukan penelitian dengan tema sentral yaitu“Penggunaan teknik permainan peran dalam bimbingan kelompok untuk meningkatkan percaya diri di PAUD IAIN Parepare".

\section{TINJAUAN TEORI}

\subsubsection{Belajar dan bermain}

Setiap anak selalu ingin bermain. bermain merupakan suatu yang menyenangkan. Hampir tidak ada permainan yang membuat anak tidak senang. 
Kadangkala, ia bermain berlama lama dalam suatu permainan, pada saat yang lain ia bermain hanya sesaat atau sebentar saja. ${ }^{1}$

Bermain dilakukan dengan atau tanpa alat permainan. Anak dapat menggunakan segala sesuatu yang ada di dekatnya untuk bermain atau hanya dengan dirinya sendiri, misalnya dengan jari-jari tangannya. Anak relatif bebas melakukan berbagai hal dalam permainan yang dilakukan. Tidak ada paksaan bagi anak harus melakukan sesuatu dalam bermain.

Dalam bermain anak melakukan berbagai kegiatan yang berguna untuk mengembangkan dirinya, anak mengamati, mengukur, membandingkan, bereksplorasi, meneliti, dan masih banyak lagi yang dapat dilakukan anak. Situasi seperti sering dilakukan tanpa kita sadari bahwa ia telah melatih dirinya dalam beberapa kemampuan tertentu sehingga ia memiliki kemampuan baru.

Jadi bermain merupakan peluang bagi anak anak untuk melakukan berbagai hal. Situasi yang membuat anak belajar, dengan demikian, bermain merupaka cara anak belajar. Belajar tentang apa saja. belajar tentang objek, kejadian,dituasi,dan konsep (misalnya halus, kasar, dan lain-lain) mereka selalu ingin tahu dengan berbagai hal yang ingin mereka lalukan selalu merasa penasaran akan sesuatu hal yang ingin dia kerjakan selalu bertanya dan selalu ingin mengetahui yang mereka lihat.

\subsubsection{Bermain sebagai metode}

Bermain merupakan suatu kegiatan yang sangat di senangi anak. Pada berbagai situasi dan tempat selalu saja anak menyempatkan untuk menggunakannya sebagai arena bermain dan permainan.

Kegiatan belajar di PAUD lebih banyak dilakukan dengan bermain. Pada dasarnya, situasi PAUD didesain sebagai arena bermain. Apa saja yang ada selalu berkaitan dengan bermain. Hal ini dapat dilihat dari penataan benda benda yang ada, warna, gambar dan peralatannya. Sehingga kalau kita memasuki lingkungan PAUD akan di sambut dengan suara riuh dan aktifitas anak yang beragam.

Bermain diartikan oleh banyak ahli dengan berbagai cara. Joan dan Utami mengutip pendapat beberapa ahli tentang bermain, yaitu:

a. Anak mempunyai energi lebih berlebih karena terbebas dari segala macam tekanan, baik tekanan ekonomis maupun sosial, sehingga mengungkapkan energinya dalam bermain.

b. Melalui kegiatan bermain, seorang anak menyiapkan diri untuk hidupnya kelak jika telah dewasa. Misalnya, dengan bermain peran serta tidak sadar ia menyiapkan diri untuk peran pekerjaannya di masa depan.

c. Melalui bermain anak melewati tahap tahap perkembangan yang sama dari perkembangan sejarah umat manusia (teori rekapitulasi). Kegiatan kegiatan

\footnotetext{
${ }^{1}$ Anita, Penilaian Perkembangan Belajar Anak Taman Kanak Kanak”,'h.32-33.
} 
seperti lari, melempar, memanjat, dan melompat merupakan bagian dari kehidupan sehari hari dari generasi ke generasi.

d. Anak bermain (berekreasi) untuk membangun kembali energy yang telah hilang. Bermain merupakan medium untuk menyegarkan badan kembali (revitalisasi) setelah bekerja berjam jam.

e. Melalui kegiatan bermain,anak memuaskan keinginan keinginannya yang terpendam atau tertekan. Dengan bermain anak seperti mencari kompesansi untuk apa yang tidak ia peroleh dalam kehidupan nyata, untuk keinginan keinginan yang tidak mendapat pemuasan.

f. Bermain juga memungkinkan anak melepaskan perasaan - perasaan dan emosinya, yang dalam realitas tidak dapat di ungkapkannya.

g. Kepribadian terus berkembang dan untuk pertumbuhan yang normal, perlu ada rangsangan (stimulus), dan bermain memberikan stimulus ini untuk pertumbuhan.

Jadi menurut pandangan tersebut bahwa bermain merupakan suatu aktifitas yang membantu anak mencapai perkembangan yang utuh,baik fisik, intelektual, social, moral, dan emosional.

Hasil penilaian harus dapat membina dan mendorong timbulnya keinginan anak untuk meningkatkan pertumbuhan dan perkembangannya. Oleh karena itu. Hasil penilaian harus di rasakan sebagai suatu penghargaan bagi yang hasil dan sebaliknya merupakan peringatan bagi yang belum hasil.namun sebagai guru harus ingat bahwa pada setiap diri anak terdapat mempunyai kelebihan kelebihan tertentu yang ada pada dirinya.

Anak usia dini sangat memerlukan pembelajaran dan perkembangan yang baik, berdasarkan hasil observasi yang di lakukan dengan kepala sekolah dan guru PAUD IAIN Parepare terdapat sebagian kelompok kelas yang memerlukan pembelajaran konsep diri kelompok yang memerlukan berumur 5-6 tahun yaitu kelas kelompok B, dan harapan harapan kepala sekolah adalah agar kedepannya anak anak kelompok $\mathrm{B}$ bisa berkembang lebih baik, agar konsep diri yang rendah bisa berkurang

Beberapa dari mereka selalu mencontek ketika mengerjakan tugas di kelas dan merasa pesimis ketika di berikan tugas tertentu, mereka malu malu sehingga guru memiliki peran penting dalam membantu mengatasi masalah tersebut, yaitu masalah rendahnya percaya diri, karena jika kualitas percaya diri anak kelompok B rendah maka kualitas masa terlaksana tidak berjalan dengan baik hasil prestasi tidak sesuai dengan harapan dan akan berpengaruh pada perkembangan ketika dewasa . (Haramain, 2012, 2016, 2019; Juddah, 2015; Rahmawati, Wahidin and Aris, 2015; Abdullah, 2016; Hidayat, 2016; Mulianah and Hidayat, 2016; Muliati, 2016; Sunubi, Dalle and Maghdalena, 2016; Anwar, 2016; Azis, Herdah and Jufri, 2016; Budiman, 
Musyarif and Firman, 2016; Ahdar, 2017; Ilham, 2017; Ipandang, 2017; Al-Amri and Haramain, 2017; Ulum and Haramain, 2017; Azis and Jufri, 2017; Khairul and Haramain, 2018; Muammar and Suhartina, 2018; Tanwir and Said, 2018)(Haramain, 2017; Ulum and Haramain, 2017)

Layanan bimbingan konseling sangat di perlukan ketika menghadapi hal yang seperti ini banyak layanan yang dapat dilakukan, dengan hal ini langkah dalam membantu masalah ketika menghadapi anak kelompok B yaitu dengan permainan peran dan bimbingan kelompok, bimbingan kelompok sangat tepat digunakan untuk meningkatkan rasa percaya diri pada anak kelompok B, di samping itu ada berbagai pendekatan Pendekatan yang dapat digunakan dalam layanan konseling kelompok teknik yang dapat digunakan dalam melaksanakan layanan konseling kelompok yaitu berkeliling, kursi kosong, dan role playing,

Tujuan pendekatan gestalt ialah untuk membantu konseli mencapai kesadaran, memanfaatkan sumber-sumber potensi pribadinya, mengurangi ketergantungan pada orang lain, meningkatkan rasa tanggung jawab, membuat pilihan yang tepat, dan memperoleh kemampuan diri. Hal ini bahwa konseli haruslah dapat berubah dari ketergantungan terhadap lingkungan atau orang lain menjadi percaya diri, dapat berbuat lebih banyak untuk meningkatkan kebermaknaan hidupnya.

Teknik role playing ini sangat membantu untuk pemecahan masalah klien yang dapat menggali sendiri masalahnya (mengeksplorasi potensi di dalam dirinya), meluapkan emosi yang terpendam serta mendapatkan pemecahan masalah yang berasal dari konselor dan anggota kelompok lainnya.

Rendahnya percaya diri terkadang menghambat pencapaian prestasi. Karena anak mempunyai perasaan takut seperti salah dalam mengerjakan tugas yang di berikan oleh guru bahkan meminta bantuan temannya untuk mengerjakan tugasnya karena kurang percaya diri yang telah dimiliki. Berbagai kelemahan pribadi menjadi sumber penurunan dan mempengaruhi tingkat kepercayaan diri.

Metode bermain peran adalah salah satu cara untuk meningkatkan rasa percaya diri pada anak usia dini. Pendidikan usia dini 4-5 tahun merupakan pendidikan paling dasar, hal ini merupakan baik untuk tahapan selanjutnya. Bermain peran atau di sebut berpura pura mempunyai sifat edukatif sangat efektif digunakan untuk melakukan proses peningkataan percaya diri ,perasaan pada anak usia dini sangat sensitive apabila ketika memberikan gambaran atau contoh yang baik anak tersebut sangat lebih cepat menanggapi apa yang mereka lihat.

\section{REFERENCES}

(1) Abdullah, B. (2016) 'KONSTITUSI PENDIDIKAN ISLAM DALAM MEMBANGUN MASYARAKAT MADANI', KURIOSITAS: Media Komunikasi Sosial Keagamaan, 9(2), pp. 79-86. 
(2) Ahdar, A. (2017) 'TINJAUAN KRITIS DAN MENYELURUH TERHADAP FUNDAMENTALISME DAN RADIKALISME ISLAM MASA KINI', KURIOSITAS: Media Komunikasi Sosial dan Keagamaan, 10(1), pp. 19-36.

(3) Al-Amri, L. and Haramain, M. (2017) 'AKULTURASI ISLAM DALAM BUDAYA LOKAL', KURIOSITAS, 10(2), pp. 87-100.

(4) Anwar, A. (2016) 'KONTRIBUSI KELUARGA TERHADAP PEMBENTUKAN KARAKTER ANAK (Studi Perspektif Modal Sosial di Kota Parepare)', KURIOSITAS, 9(1), pp. 57-65.

(5) Azis, A. and Jufri, M. (2017) 'IMPLEMENTASI NILAI-NILAI AJARAN TAU LOTANG TERHADAP MASYARAKAT LOKAL WATTANG BACUKIKI KOTA PAREPARE', KURIOSITAS: Media Komunikasi Sosial dan Keagamaan, 10(2), pp. 23-41.

(6) Azis, S. A., Herdah, H. and Jufri, M. (2016) 'IMPLEMENTASI MODEL PEMBELAJARAN KOOPERATIF MAHASISWA PROGRAM STUDI BAHASA ARAB STAIN PAREPARE (Studi Pengembangan Pembelajaran Mata Kuliah Serumpun)', KURIOSITAS, 9(1), pp. 81-102.

(7) Budiman, B., Musyarif, M. and Firman, F. (2016) 'IDEOLOGI BULETIN DAKWAH AL-ISLAM DALAM KAJIAN WACANA KRITIS', KURIOSITAS, 9(1), pp. 21-34.

(8) Haramain, M. (2012) 'Pemikiran dan Gerakan Dakwah Tuan Guru M. Zainuddin Abdul Madjid di Lombok NTB'. Makassar: Universitas Islam Negeri Alauddin Makassar.

(9) Haramain, M. (2016) 'al-Wasathiyyah wa Atsaruha fi al-da'wah al-Islamiyyah: Dirasah Lugawiyyah Manhajiyyah', Langkawi: Journal of The Association for Arabic and English, 2(1), pp. 83-100.

(10) Haramain, M. (2017) 'DAKWAH DALAM ARUS GLOBALISASI MEDIA: PELUANG DAN TANTANGAN', KOMUNIDA: MEDIA KOMUNIKASI DAN DAKWAH, 7(1), pp. 60-73.

(11) Haramain, M. (2019) Prinsip-prinsip Komunikasi dalam al-Qur'an. Parepare: IAIN Parepare Nusantara Press.

(12) Hidayat, W. (2016) 'PERSEPSI SISWA SMA KOTA PAREPARE TENTANG STAIN PAREPARE', KURIOSITAS: Media Komunikasi Sosial Keagamaan, 9(1), pp. 4956.

(13) Ilham, M. I. M. (2017) 'HERMENEUTIKA AL-QUR'AN', KURIOSITAS: Media Komunikasi Sosial dan Keagamaan, 10(2), pp. 101-119.

(14) Ipandang, I. (2017) 'FILSAFAT AKHLAK DALAM KONTEKS PEMIKIRAN ETIKA MODERN DAN MISTISISME ISLAM SERTA KEMANUSIAAN', KURIOSITAS: Media Komunikasi Sosial dan Keagamaan, 10(1), pp. 1-18.

(15) Juddah, A. B. (2015) 'ANALITIS SINTETIK TERHADAP STRATEGI PEMBELAJARAN ANDRAGOGI BERPERSPEKTIF KEMANDIRIAN DOSEN DALAM PEMBELAJARAN', Kuriositas: Media Komunikasi Sosial dan Keagamaan, 8(2), pp. 41-45.

(16) Khairul, K. and Haramain, M. (2018) 'Aplikasi Digital Risalah Ilmu Tajwid dalam Meningkatkan Kemampuan Baca Al Qur'an', KURIOSITAS: Media Komunikasi Sosial dan Keagamaan, 11(2), pp. 145-157.

(17) Muammar, M. and Suhartina, S. (2018) 'Media Pembelajaran Berbasis Teknologi Informasi Dalam Meningkatkan Minat Belajar Akidah Akhlak', KURIOSITAS: Media Komunikasi Sosial dan Keagamaan, 11(2), pp. 176-188.

(18) Mulianah, S. and Hidayat, W. (2016) 'PENGEMBANGAN TES BERBASIS 
KOMPUTER', KURIOSITAS: Media Komunikasi Sosial dan Keagamaan, 9(2), pp. 27-43.

(19) Muliati, M. (2016) 'PENGARUH PAHAM KEAGAMAAN TERHADAP ETOS KERJA PEDAGANG PASAR SENTRAL KABUPATEN PINRANG', KURIOSITAS: Media Komunikasi Sosial Keagamaan, 9(2), pp. 101-115.

(20) Rahmawati, R., Wahidin, W. and Aris, A. (2015) 'MATERI FIQH IBADAH DAN IMPLEMENTASINYA BAGI MAHASISWA JURUSAN SYARIAH STAIN PAREPARE', KURIOSITAS: Media Komunikasi Sosial Keagamaan, 8(1), pp. 71-86.

(21) Sunubi, A. H., Dalle, A. and Maghdalena, M. (2016) 'ENGLISH TEACHER INSTRUCTION IN GIVING MATERIAL BY USING CODE SWITCHING AND CODE MIXING IN SMU NEG. 2 PAREPARE', KURIOSITAS, 9(1), pp. 35-47.

(22) Tanwir, T. and Said, H. (2018) 'Inovasi Pembelajaran Guru Pendidikan Agama Islam Berbasis Teknologi Informasi', KURIOSITAS: Media Komunikasi Sosial dan Keagamaan, 11(2), pp. 189-210.

(23) Ulum, A. C. and Haramain, M. (2017) 'EKSISTENSI DAKWAH DALAM MERESPON PLURALISME', KOMUNIDA: MEDIA KOMUNIKASI DAN DAKWAH, 7(2), pp. 124-138. 